\title{
O SEGREDO DE ARTHUR CLARKE: UM MODELO SEMIÓTICO PARA TRATAR QUESTÕES SOCIAIS DA CIÊNCIA USANDO A FICÇÃO CIENTÍFICA
}

\author{
Luís Paulo de Carvalho Piassi*
}

RESUMO: O uso da ficção científica no ensino de Ciências tem sido proposto por diversos autores. Neste trabalho lançamos mão da semiótica greimasiana, que considera a significação do texto sob o ponto de vista narrativo, para a análise de um conto de Arthur Clarke. Consideramos o texto a partir dos três níveis propostos pela teoria de Greimas: o discursivo, o narrativo e o fundamental. Pela articulação desses níveis construímos um modelo de análise baseado no nível discursivo, especificamente na relação entre tema e figura, para funcionar como ferramenta para se mapearem os temas sociais e políticos conexos com a ciência em obras de ficção científica, para a elaboração de atividades didáticas que não se restrinjam à simples discussão conceitual.

Palavras-chave: Ficção científica, ensino de Ciências, semiótica

THE SECRET OF ARTHUR CLARKE: A SEMIOTIC MODEL FOR APPROACHING SOCIAL ISSUES OF SCIENCE USING THE SCIENCE FICTION

ABSTRACT : The use of science fiction in Science teaching has been proposed by several authors. In this paper we use the greimasian semiotics, which considers the meaning of the text from a narrative point of view, to analyze a short story by Arthur Clarke. We consider a text from the three levels proposed by the Greimas theory: the discursive, the narrative and the fundamental. By articulating these levels we build up an analysis model based in the discursive level, specifically on the relationship between theme and figure, for using it as a tool for mapping social and political themes concerned with science in fictional works, to building up classroom activities not restricted to mere conceptual discussions.

Keywords: Science fiction, science teaching, semiotics. 


\section{INTRODUÇÃO}

A ficção científica tem sido empregada como recurso didático para o ensino de ciências naturais, conforme apontam diversos autores (FREUDENRICH, 2000; NEVES et al, 2000; BRAKE e THORNTON, 2003; ROSE, 2003; DARK, 2005; GOMES-MALUF e SOUZA, 2008; MACHADO, 2008). Obras de ficção são manifestações artísticas e, na grande maioria das vezes, não são produzidas com objetivos escolares. Dessa forma, o uso da ficção em sala de aula somente se justifica na medida em que permita explorar elementos que outros recursos concebidos com finalidades especificamente didáticas não possam proporcionar. Em trabalhos anteriores, temos proposto que o uso da ficção científica é particularmente interessante quando entendemos o conteúdo escolar a partir de uma perspectiva que considera não apenas os aspectos conceituais e fenomenológicos das ciências, mas também a abordagem de temas ligados ao fazer científico e às relações que a ciência estabelece com outros âmbitos da cultura humana. A partir dos trabalhos de Libâneo (1990) e Zanetic (1989), temos proposto que se considere a partir de três esferas o conteúdo escolar de Ciências, ou saber a ensinar (BOSCH et al, 2006). Essas esferas são as seguintes:

- esfera conceitual-fenomenológica (Esfera C): inclui conceitos, leis e fenômenos associados à ciência, bem como aplicações, tecnologias, normas técnicas e outros conhecimentos que possam ser considerados produtos da atividade científica e tecnológica;

- esfera histórico-metodológica (Esfera $H$ ): inclui conhecimentos a respeito dos processos de produção de conhecimento científico e tecnológico, que podem se dar através do exame histórico (diacrônico) ou sincrônico de tais processos, levando a questionamentos da própria natureza da ciência e da tecnologia, a partir de sua lógica interna;

- esfera sócio-política (Esfera S): aqui incluímos as interações entre ciência e tecnologia com o contexto mais amplo da sociedade, incluindo questões econômicas, políticas e culturais, particularmente procurando evidenciar visões ideológicas a respeito da ciência.

Nessa perspectiva, a esfera C poderia ser considerada a esfera dos produtos da ciência, entendendo-se produtos como os resultados, em termos de conhecimento, da atividade científica e tecnológica. É importante observar que ao falarmos de produtos não estamos nos referindo a produtos físicos, mas a saberes. Por exemplo, não estamos falando da bomba atômica, objeto físico, mas sim da concepção do que é uma bomba atômica, os conceitos, os fenômenos, as convenções técnicas e outros saberes nela envolvidos. A esfera $\mathrm{H}$ seria então a esfera dos processos internos da ciência e da tecnologia que levam à produção dos conhecimentos da esfera C. Esses processos tanto podem ser entendidos em seu sentido histórico quanto em seu sentido epistemológico. Em outras palavras, podemos falar do desenvolvimento histórico do conceito de fissão nuclear assim como podemos nos 
O segredo de Arthur Clarke: um modelo semiótico para tratar questões sociais da ciência usando a ficção científica

preocupar com os aspectos epistemológicos a ele conexos. Nesse sentido, tais conteúdos não são produtos da atividade dos cientistas. Entretanto, constituem também saberes sistematizados, produzidos em outros âmbitos, tais como a historiografia da ciência e a filosofia da ciência. Por fim, a esfera $\mathrm{S}$ pode ser considerada a esfera das relações que a ciência e a tecnologia travam com outros âmbitos da cultura e da sociedade humana, tais como a política, a religião, a arte, a economia, etc. Essas relações evidentemente possuem naturezas as mais diversas e são relações de mão dupla, por exemplo, da ciência para a arte e da arte para a ciência. É interessante notar mais uma vez estamos falando aqui de saberes relativos a essas relações e que esses saberes não são sistematizados pela atividade do físico, do químico ou do astrônomo (como tais), cujo produto é aquilo que se encontra na esfera C.

Se empregarmos a terminologia da Teoria Antropológica da Didática, derivada dos trabalhos de Chevallard (CHEVALLARD, 1985; BOSCH et al, 2006), podemos dizer que a diferenciação das três esferas está na origem do chamado saber sábio em cada uma delas de acordo com o ilustrado na figura 1.

No presente trabalho procuramos mostrar de que forma tais esferas se articulam no discurso de uma obra de ficção científica e quais os desdobramentos dessa articulação nas possibilidades de uso didático desse tipo de obra. Estamos particularmente interessados em examinar de que forma as esferas aparecem concretamente inscritas no discurso da ficção científica, de forma que se possa estabelecer a existência de uma hierarquia de saberes nesse discurso e identificar claramente onde está e qual o papel dos saberes derivados de cada esfera na constituição da mensagem ficcional.

Figura 1: Esferas do saber a ensinar e sua origem no saber sábio

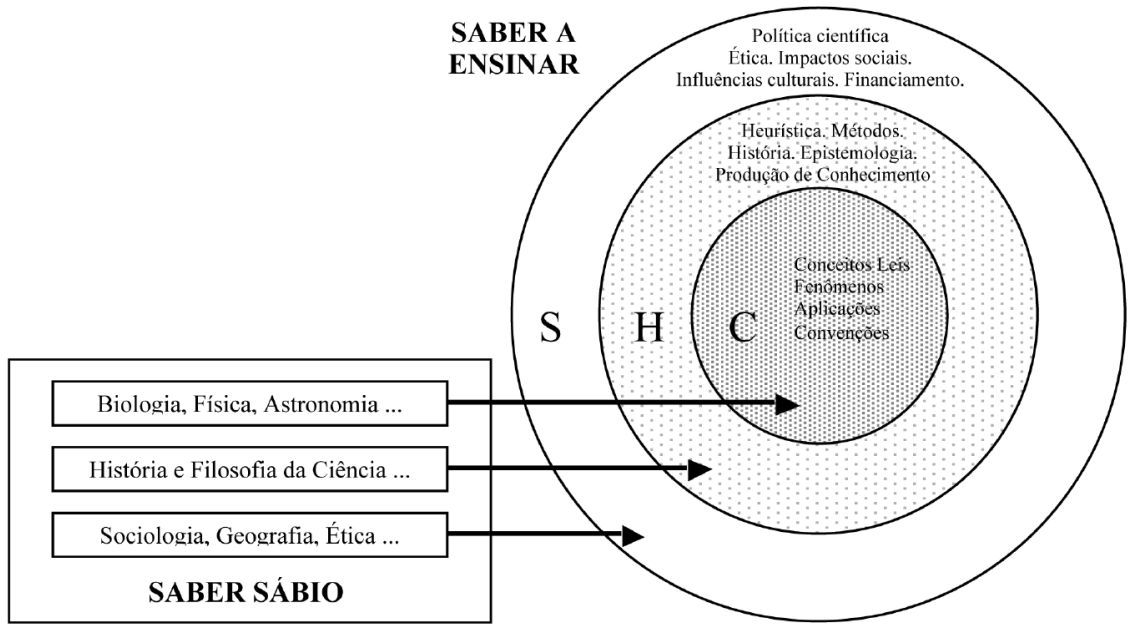


Nosso interesse fundamental, entretanto, está situado na esfera S. Entendemos que as obras de ficção científica, por suas características, articulam discussões sociopolíticas da ciência com questões conceituais e metodológicas, e esse pode ser um dos principais aspectos que tornam o gênero especialmente interessante para aplicações didáticas. Entretanto, a identificação de temas sociais e posições ideológicas que um dado texto veicula está longe de ser um procedimento óbvio, sobretudo para olhares destreinados. A semiótica de Greimas (1973), nesse sentido, fornece instrumentos teóricos que permitem evidenciar aspectos da significação dos textos. Neste trabalho, tomando como base um texto específico o conto "O Segredo", de Arthur C. Clarke (1971) - aplicaremos elementos da teoria greimaisiana para construir um modelo de interpretação de textos de ficção científica, que julgamos ser aplicável a outros textos e de utilidade na identificação de conteúdos sociocientificos para abordagem didática.

\section{A semiótica de Greimas}

A metodologia que empregamos é baseada na semiótica derivada do trabalho de A. J. Greimas (GREIMAS, 1973; GREIMAS e COURTÉS, 2008). Um dos pontos centrais desse instrumento teórico é a consideração do texto do ponto de vista narrativo. Analogamente à análise sintática do nível da frase, a semiótica considera que o texto possui elementos que guardam entre si relações sintáxicas definidas. Para ela, qualquer narrativa pode ser considerada a partir de três níveis gradativamente mais abstratos: o discursivo, o narrativo e o fundamental (FIORIN, 2009, p. 20). Tal análise em camadas, articuladas entre si, é denominada percurso gerativo de sentido. A tabela 1 resume essa estrutura e apresenta algumas categorias-chave de cada um dos níveis.

Tabela 1: Níveis do percurso gerativo do sentido e seus elementos

\begin{tabular}{|l|l|}
\hline \multicolumn{1}{|c|}{ Discursivo } & \multicolumn{1}{|c|}{ Atores, tempo e espaço I Figuras e Temas } \\
\hline Discursivo & Atores, tempo e espaço I Figuras e Temas \\
\hline Narrativo & Sujeito e objeto de valor I Actantes I Programa narrativo \\
\hline Fundamental & Contrariedade de valores (axiologias) I Transformações \\
\hline
\end{tabular}

Tomemos como exemplo a famosa história de Chapeuzinho Vermelho. O nível discursivo é aquele em que temos a Chapeuzinho Vermelho, o lobo e assim por diante. Esse é o nível do texto mais concreto e superficial e também o mais complexo na medida em que considera os detalhes expressos literalmente. Nele, Chapeuzinho é uma menina que carrega uma cesta com doces (atores), mora em um dado reino, numa casa próxima a um bosque (espaço) e vive em uma dada época 
O segredo de Arthur Clarke: um modelo semiótico para tratar questões sociais da ciência usando a ficção científica

(tempo). Esses elementos constituem a actorialização e a espacialização e temporalização. Também no nível discursivo, consideramos a relação entre figuras e temas: Chapeuzinho pode ser uma figuração para a ingenuidade, que seria o tema. Essa figura se sustenta em alguns elementos trazidos pela actorialização: uma menina, pequena, meiga, com roupas delicadas, sozinha na floresta, por um lado, e um lobo, malvado, mal-intencionado e mentiroso, que se opõe a ela.

No nível narrativo, mais profundo e abstrato, Chapeuzinho, despida de seus detalhes, é convertida no sujeito da narrativa que parte em busca de um objeto de valor, que poderia ser o reconhecimento, nesse caso associado ao ser adulto, capaz de compreender o mundo e lidar com os perigos. O sujeito é um actante, definido por Greimas e Courtés (2008, p.20) como "aquele que realiza ou sofre o ato, independentemente de qualquer outra determinação”. A semiótica greimasiana evita o uso de termos como "personagem", uma vez que esses se referem a concretizações específicas, enquanto actante pode ser qualquer agente, que realiza ou sofre um ato, por exemplo, uma força agindo sobre um corpo, em um texto de física. No exemplo, o lobo corresponde ao actante antissujeito, ou seja, aquele que se opõe ao programa narrativo do sujeito. Entre outros actantes que podem existir estão os destinadores da manipulação e da competência, desempenhados aqui pela mãe de Chapeuzinho, conforme explicaremos adiante.

Em uma narrativa canônica, o sujeito busca seu objeto de valor passando por quatro etapas: manipulação, competência, performance e sanção (FIORIN, 2009, p. 29). Na manipulação, primeira etapa do nível narrativo, o sujeito recebe do destinador manipulador um objeto modal de querer ou de dever, que é o que o coloca em ação. Na nossa história a mãe instaura o dever em Chapeuzinho. A preparação do sujeito para a ação é denominada competência, e essa é a fase em que ele adquire os chamados objetos modais do poder (a cesta com os doces) e do saber (conhecer o caminho da casa da vovó, ouvir as advertências da mãe). Somente após a competência pode ocorrer a fase da performance, quando a ação é efetivamente realizada, com a entrega dos doces propriamente dita. Finalmente, a sanção é a fase em que os resultados são reconhecidos, e eventuais segredos são revelados, podendo haver um prêmio para o sujeito bem sucedido, ou punição no caso contrário. A tabela 2 resume as etapas do nível narrativo.

Tabela 2: Etapas do nível narrativo

\begin{tabular}{|l|l|}
\hline Manipulação & Instauração do sujeito I Destinador manipulador I Querer e Dever \\
\hline Competência & Preparação I Destinador da competência I Poder e Fazer \\
\hline Performance & Ação I Conjunção (ou não) com objetos de valor \\
\hline Sanção & Avaliação I Premiação, punição, revelação \\
\hline
\end{tabular}


O nível fundamental considera a relação de conjunção e disjunção do sujeito com o objeto de valor, considerando as dicotomias semânticas e o trajeto entre estados. No exemplo, se o objeto de valor é o reconhecimento, podemos imaginar um termo contrário que se opõe a ele. Ao considerarmos Chapeuzinho como figuração da ingenuidade, inocência, ou imaturidade, podemos entender a história como uma oposição entre "ingenuidade" e "maturidade", que seriam os chamados termos primários de uma dicotomia semântica a partir da qual a narrativa pode ser entendida. Chapeuzinho representaria assim um sujeito em busca do reconhecimento de sua maturidade. O trajeto do sujeito nunca passa diretamente de um estado para o seu contrário (FONTANILLE, 2008, p.64), mas há sempre um passo intermediário, denominado contraditório, que realiza a negação dos polos contrários - no exemplo, através dos valores negação da ingenuidade e negação da maturidade. Assim, o sujeito pode passar do estado de ingenuidade para o de negação da ingenuidade e deste para a afirmação da maturidade. Isso poderia ser exemplificado pela sequência em que Chapeuzinho é abordada pelo lobo na floresta (ingenuidade), quando ela estranha os aspectos físicos do lobo disfarçado como avó (negação da ingenuidade) e quando ela é devorada pelo lobo, descobrindo a verdade (maturidade). Esse sistema de contrários e contraditórios é comumente representado em um diagrama denominado quadrado semiótico (FONTANILLE, 2007, p.65; GREIMAS e COURTÉS, 2008, p. 400), que mostra os trajetos possíveis dentro do nível fundamental.

Figura 2: Quadrado semiótico representando o trajeto de Chapeuzinho Vermelho

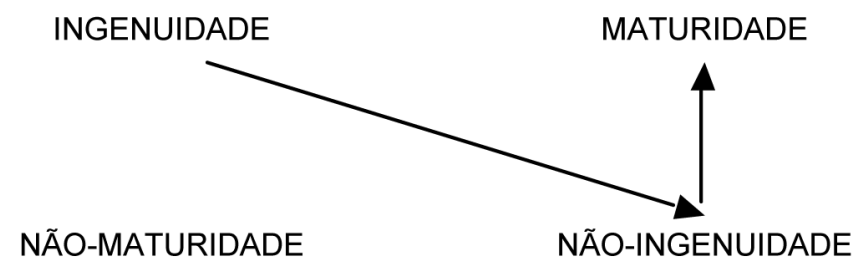

A análise ideológica de um texto pode ser realizada quando verificamos associações arbitrárias entre pares de valores semânticos. Por exemplo, além da oposição ingenuidade/maturidade verificamos também nessa história a dicotomia feminino/masculino (a menina e o lobo) e uma associação entre "feminino" e "ingenuidade", de forma que identificamos aí um dos pontos de vista implícitos no texto: a ingenuidade associada ao gênero feminino.

Antes de prosseguir, detalhemos a fase da manipulação, cujos aspectos empregaremos mais adiante. Nela, o sujeito se estabelece ao ser dotado de (ou conjugado a) um querer ou de um dever que o coloca em ação por meio de um actante manipulador, que emprega para isso quatro estratégias principais: a tentação, a se- 
O segredo de Arthur Clarke: um modelo semiótico para tratar questões sociais da ciência usando a ficção científica

dução, a intimidação ou a provocação. As duas primeiras são baseadas em uma relação positiva com o sujeito e instauram o querer. As duas últimas são baseadas em uma relação negativa com o sujeito e instauram o dever (PIETROFORTE, 2007, p 17). A tentação consiste em se oferecer uma recompensa, enquanto a intimidação consiste em se ameaçar com uma punição. As duas baseiam-se no poder, na medida em que o manipulador dispõe dos meios para concretizar seja a recompensa, seja a punição. Já a sedução e a provocação se estabelecem, respectivamente, por uma imagem positiva ou negativa do sujeito face ao manipulador, sendo assim baseadas no saber. Na história de Chapeuzinho, a personagem é confrontada com uma confiança implícita por parte da mãe em sua condição de pessoa capaz de realizar uma tarefa dada (imagem positiva), que envolve certo perigo, tratando-se assim de uma sedução. A tabela 3 resume essas ideias.

Tabela 3: Modalidades de manipulação

\begin{tabular}{|l|l|l|}
\hline & \multicolumn{1}{|c|}{ Poder } & \multicolumn{1}{c|}{ Saber } \\
\hline Positiva & Tentação & Sedução \\
\hline Negativa & Intimidação & Provocação \\
\hline
\end{tabular}

A semiótica greimasina, como instrumento teórico, constitui-se, portanto, em um procedimento heurístico cuja principal contribuição é justamente "evidenciar o óbvio". Embora depois de uma análise semiótica de uma história como Chapeuzinho Vermelho tudo pareça muito evidente, entendemos que o procedimento que leva a essas conclusões não é trivial, e o uso desse ferramental se justifica como um auxílio na análise de textos que podem servir como base para a elaboração de atividades didáticas, se não por professores na sala de aula, ao menos por elaboradores de propostas e projetos de ensino, nas universidades, editoras e secretarias de educação. Apliquemos agora alguns desses elementos a um conto modelo.

\section{0 segredo: um conto modelo}

Arthur Clarke foi um dos mais conhecidos escritores de ficção científica do século XX. Sua obra mais difundida é possivelmente o filme "2001: uma odisseia no espaço", do qual foi o roteirista e que é bastante empregado como recurso didático em aulas de Física (BORGWALD et al, 1993; NEVES, 2000) por retratar com surpreendente fidelidade os movimentos dos artefatos em um ambiente espacial. Clarke é considerado um escritor de ficção científica hard, ou seja, que incorpora com intensidade e de forma coerente conceitos e leis científicas em suas obras ficcionais (ALLEN, 1976, p. 21). O conto "O segredo" integra uma coletâ- 
nea denominada O Vento Solar, escrita nas décadas de 1960 e 1970, em concomitância com o auge da corrida espacial russo-americana.

Uma das razões para empregarmos esse conto como modelo de análise, além de ele ser curto e interessante, é o fato de que ele explora claramente um conceito físico amplamente abordado no ensino médio: a força gravitacional e a diferença entre massa e peso. Além disso, aborda questões sobre a atividade científica e relações entre ciência e sociedade, conforme já tivemos oportunidade de mostrar em outros trabalhos. O que pretendemos mostrar é como o emprego da semiótica nos permite identificar e mapear a presença desses temas no texto da obra e seus possíveis desdobramentos que podem nos levar a um melhor aproveitamento didático. Nossa técnica de abordagem consiste em aplicar os conceitos semióticos não apenas à narrativa principal, mas às narrativas subordinadas, em um processo que permite a extração de considerações a respeito de conceitos científicos e suas representações socioculturais inscritas no discurso da obra.

"O segredo" conta a história de um jornalista científico em visita a uma instalação de pesquisa na Lua, em um futuro em que a Terra está superpovoada. Ele suspeita que algo estranho ocorra na base e acredita que os cientistas estejam escondendo uma descoberta potencialmente sensível, que poderia afetar a população como um todo. O conto se inicia da seguinte forma:

Fazia duas semanas que Henry Cooper estava na Lua quando descobriu que havia por ali algo de anormal. A princípio foi apenas uma suspeita mal definida, essa espécie de palpite que um repórter científico, com seu espírito realista, não leva muito a sério (CLARKE, 1971, p. 79).

O conto introduz imediatamente seu personagem principal, Henry Cooper, que é caracterizado como repórter científico. No nível discursivo temos a instauração do espaço (Lua), do tempo (futuro próximo) e da pessoa (repórter científico). No nível narrativo o trecho acima mostra um actante sujeito (actorializado por Henry Cooper) em busca de um objeto de valor (o conhecimento). Esse segmento estabelece um programa narrativo em que o repórter partirá em busca de desvendar o suposto segredo. Trata-se da manipulação de categoria provocação, pois se pressupõe um risco à imagem do jornalista, que tem a obrigação moral de desvendar segredos. O segredo em si é o manipulador, que desafia o jornalista. Nesse pequeno trecho já observamos oposições de valores, concretizadas pelo confronto entre "científico" e "realista", de um lado, e "suspeita" e "palpite", de outro: um repórter científico e realista não deve se deixar levar por palpites e suspeitas. Aqui já temos afirmações que veiculam uma visão a respeito do que é ser "científico": a afirmação de "realista" e a negação de "palpites" e "suspeitas". O objeto de valor a ser alcançado é o conhecimento, associado aqui, à verdade.

Um segundo trecho traz elementos que nos permitem estabelecer algumas figuras empregadas no conto: 
O segredo de Arthur Clarke: um modelo semiótico para tratar questões sociais da ciência usando a ficção científica

A AENU sempre dera grande importância às relações públicas - especialmente na hora de ser elaborado o orçamento, quando o mundo superpovoado clamava por mais estradas, escolas e fazendas marítimas, queixando-se dos bilhões que estavam sendo desperdiçados (CLARKE, 1971, p. 79).

A AENU é uma instituição (fictícia) chamada Administração Espacial das Nações Unidas e corresponde a um sujeito em busca do objeto de valor "verbas", que se depara com o antissujeito "mundo superpovoado" que age para manter a o sujeito em disjunção com seu objeto de valor. Essa narrativa é subordinada à narrativa principal em que Henry Cooper desempenha o papel de sujeito. Articulando as duas, podemos estabelecer associações abstratas que permitem mapear a estratégia figurativa do texto.

Henry Cooper chega à Lua, onde há uma estação de pesquisa, na qual ele percebe situações estranhas. Seu programa narrativo é investigar o que está acontecendo de errado (conjunção com o saber). A relação entre Cooper e a estação de pesquisa é de desconfiança, vigilância, investigação. Relações semelhantes se estabelecem entre o "mundo superpovoado", representando aqui a população em geral, em relação à entidade que gasta o orçamento com pesquisa científica, a AENU. Temos, então, dois pólos em polêmica, de um lado a ciência, figurativizada pela AENU e pela Estação Lunar, de outro a opinião pública, figurativizada por Henry Cooper e pelo mundo superpovoado. Notemos que "ciência" aqui se refere a instituições que manipulam recursos financeiros e são dotadas de poder de decisão sobre prioridades sociais e não como uma atividade de produção de conhecimento e desenvolvimento cultural. Essas duas possibilidades configuram duas instâncias distintas, a primeira ligada ao poder (ciência como poder) e a outra ligada ao saber (ciência como saber), que de certa forma constituem um confronto entre dois valores abstratos: o valor material (associado ao poder) e o valor existencial (associado ao saber).

Tabela 4 - Campos em polêmica em "0 segredo" e seus representantes

\begin{tabular}{|l|l|}
\hline \multicolumn{1}{|c|}{ Ciência (como poder) } & \multicolumn{1}{c|}{ Opinião Pública } \\
\hline AENU & Henry Cooper \\
\hline Estação Lunar & Mundo superpovoado \\
\hline
\end{tabular}

Estabelecemos aqui uma questão ligada à esfera $\mathrm{S}$, que é a polêmica entre ciência e opinião pública. O que está em jogo é a difusão da informação e o uso dos recursos financeiros. A lógica da argumentação nos leva a formular o ponto de vista da opinião pública da seguinte forma:

(1) O povo faz sacrifícios para financiar a pesquisa científica.

(2) Assim, a ciência deve prestar contas das informações que obtém. 
A partir disso, podemos compreender melhor a etapa da manipulação. O sujeito "Opinião Pública" é colocado em ação na busca do objeto de valor "Conhecimento" por conta de uma intimidação, uma vez que o querer é estabelecido em função de uma suposta ameaça derivada de uma descoberta mantida em segredo. O antissujeito "Ciência" é instado a permitir a conjunção do sujeito "Opinião Pública" com o objeto de valor "Conhecimento".

Vejamos em que termos se dá o desenvolvimento dessa questão, em seu imbricamento com o aspecto conceitual. Cooper trava contato com Chandra, um policial que o ajuda quando ele vai até a Lua. No nível narrativo, esse tipo de actante é denominado adjuvante do sujeito (GREIMAS e COURTÉS, 2008, p.23). Cooper comenta com Chandra sua preocupação e levanta a hipótese de ter sido descoberta alguma doença de origem alienígena:

\begin{abstract}
Eu mesmo escrevi artigos provando que as formas de vida em outros planetas têm químicas tão diferentes que não podem entrar em reação conosco, e que todos os nossos micróbios e parasitos levaram milhões de anos para se adaptar aos nossos organismos. Mas sempre tive minhas dúvidas a esse respeito. Suponhamos que uma nave tenha voltado de Marte com alguma coisa muito virulenta... e os médicos não tenham meios de combatêla (CLARKE, 1971, p. 82).
\end{abstract}

Nesse ponto, Cooper se coloca em um papel peculiar. É interessante notar que, como jornalista científico, seu papel seria a divulgação de notícias e não o de provar seja o que for. O mais curioso é que o sentido da palavra "provar" é questionado pela própria lógica do texto, pois o personagem prova algo de que ele tem dúvidas. Esse ponto abre uma discussão no âmbito da esfera $\mathrm{H}$, que poderia ser explorada, mas que não aprofundaremos neste trabalho. Cabe, no entanto, a observação de que estamos diante de um actante que estabelece uma proposição, e dá um julgamento a ela inicialmente com valor de verdade, depois com negação de verdade. A proposição se dá na forma da oração subordinada: "as formas de vida [...] não podem entrar em reação conosco". Temos aqui uma pequena narrativa, em que o sujeito são as formas de vida em outros planetas, o objeto de valor é "entrar em reação conosco", e o antissujeito, as "químicas tão diferentes".

A estrutura dessa pequena narrativa poderia dar origem a uma discussão no âmbito conceitual, ou seja, na esfera C. Com isso, percebemos como uma história de ficção científica hard baseia seus argumentos em conceitos científicos (lembrando, claro, que se trata de uma ciência ficcional ${ }^{1}$, não necessariamente correspondente à ciência do mundo real), o que permite uma articulação entre discussões nos três âmbitos, S, H e C, com o último estabelecendo uma espécie de base sobre a qual os demais se sustentam. Como a linha da doença alienígena é descartada da narrativa, é interessante examinarmos o desfecho da história. Chandra leva Cooper ao laboratório do cientista Dr. Hastings, que acaba revelando a descoberta: os hamsters usados como cobaia vivem muito além do tempo normal de vida da espécie. Cooper não compreende as causas nem as implicações desse 
O segredo de Arthur Clarke: um modelo semiótico para tratar questões sociais da ciência usando a ficção científica

fato, o que leva o Dr. Hastings a elaborar uma explicação:

$\mathrm{Na}$ Terra - disse ele - passamos a vida inteira lutando contra a gravidade. Ela desgasta os nossos músculos, estira e deforma os nossos estômagos. Em setenta anos, quantas toneladas de sangue o coração bombeia a uma distância de quantas milhas? E todo esse trabalho, todo esse esforço é reduzido a um sexto aqui na Lua, onde um ser humano de oitenta quilos pesa apenas catorze. (CLARKE, 1971, p. 84).

Nessa pequena narrativa, colocada na voz do cientista em discurso direto, temos instaurado o sujeito "Nós" e o antissujeito "Gravidade". O sujeito "Nós" está em busca da conjunção com o objeto de valor "Sobrevivência", ou melhor, "Vida", sofrendo, porém, oposição do antissujeito "Gravidade". Essa narrativa, que é a chave do conto, se articula de forma interessante à narrativa principal. A idéia trazida no conto desde o princípio e reforçada no final é que a Terra sofre da falta de recursos para alimentar uma população excessiva. Em outras palavras, o actante "população" também está em busca do objeto de valor "vida", que é um dos pólos da oposição semântica universal vida/morte (GREIMAS e COURTÉS, 2008, p. 535) e pode ser representada no quadrado semiótico da seguinte forma:

Figura 3: Quadrado semiótico vida vs. morte

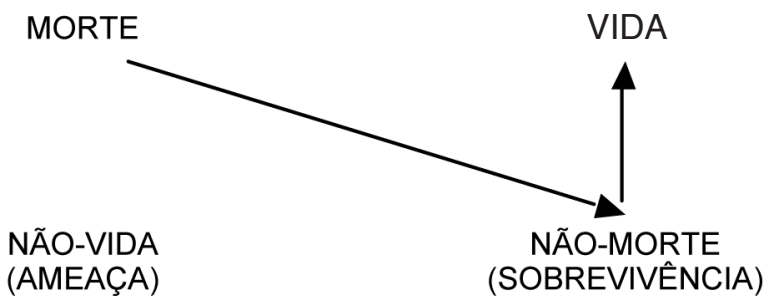

Os termos entre parêntesis são uma lexicalização (GREIMAS e COURTÉS, 2008, p. 284) dos contraditórios abstratos aplicada ao contexto da narrativa que estamos analisando, ou seja, a associação dos contraditórios a valores semânticos definidos, de acordo com texto. Nas duas narrativas temos um sujeito que está na condição de não vida. No primeiro, o "nós", gênero humano, luta contra a gravidade que nos afasta do objeto de valor vida em direção à morte, nos colocando sob ameaça. A mesma lógica se aplica ao sujeito "população", que está ameaçado pelas condições limitadas de recursos na Terra. Há uma identificação entre "nós" e "população", que é acentuada pelo desfecho da história. O Dr. Hastings explica a Cooper que a longevidade anormal dos hamsters levou os cientistas, após considerarem diversas hipóteses para explicar o fenômeno (esfera $\mathrm{H}$ ), a supor que a menor intensidade da atração gravitacional lunar poderia ser a responsável. Isso poderia implicar que o mesmo ocorresse ao outros seres vivos. Com isso, a 
remoção parcial do antissujeito "gravidade" traria o sujeito "nós" mais próximo ao objeto de valor "vida". A questão interessante, que acentua a dimensão polêmica do conto, é que, sendo isso verdade, a divulgação da informação produziria no sujeito "população" um querer em relação à Lua, ou seja, todo mundo desejaria se mudar para o satélite. Esse é o argumento central do cientista para não haver divulgado a descoberta:

- Pense neles lá em cima (...). Seis bilhões de criaturas, enchendo todos os continentes até as bordas, e agora derramando-se pelos fundos de mar. E aqui (...), nós, apenas cem mil, num mundo quase vazio. Mas um mundo em que são precisos milagres de tecnologia e engenharia simplesmente para existirmos, onde um homem com apenas 150 de QI nem sequer pode conseguir emprego. E agora descobrimos que podemos viver duzentos anos. Imagine qual será a reação deles quando souberem isso!

Há um contraste intensificado aqui entre / escassez/ e / privilégios/, que formam mais uma oposição semântica do nível fundamental do texto. De um lado, a população da Terra sofre com a escassez de recursos. De outro, a ciência (como poder) utiliza parte desses escassos recursos na pesquisa. Os cientistas são privilegiados na medida em que contam com condições muito especiais. No trecho, mostra-se que apenas algumas pessoas podem almejar viver na Lua, já que a manutenção desse ambiente consome muitos recursos e só se justifica por que supostamente pessoas muito capazes estão trabalhando lá em prol da humanidade. O Dr. Hastings coloca Henry Cooper em um dilema: ele deve compartilhar a informação com a opinião pública? A questão se torna interessante porque em princípio Cooper representa a opinião pública e deveria ser leal a ela; ele enfrenta, conforme discutimos em relação à manipulação do sujeito, uma provocação de dever moral. Porém, a divulgação da notícia pode provocar problemas maiores. Os princípios de Cooper são colocados em jogo, porque a narrativa, que encaminhava uma identificação entre "opinião pública" e "humanidade" subitamente as coloca em oposição. O interesse da humanidade, de acordo com o desfecho, não é necessariamente igual ao interesse da opinião pública. A quem Cooper deve lealdade? O texto não responde a essa questão e, dessa forma, coloca o leitor na mesma posição de Cooper. Se agruparmos algumas das dicotomias semânticas do texto, podemos estabelecer algumas das posições ideológicas nele veiculadas. A tabela 5 agrupa valores semânticos que se opõem e suas relações de associação: 
O segredo de Arthur Clarke: um modelo semiótico para tratar questões sociais da ciência usando a ficção científica

Tabela 5 - Dicotomias semânticas em associação em “0 Segredo"

\begin{tabular}{|l|l|}
\hline Vida & Morte \\
\hline Lua & Terra \\
\hline Cientista & Cidadão comum \\
\hline Privilégios (verbas) & Escassez \\
\hline Conhecimento & Ignorância \\
\hline Minoria & Maioria (superpopulação) \\
\hline Imponderabilidade & Gravidade \\
\hline
\end{tabular}

De um lado temos o cientista, detentor do conhecimento, que desfruta de privilégios de verbas e que constitui uma minoria que vive em um local pouco povoado, a Lua, que por conta da imponderabilidade dá a ele a possibilidade de viver mais. De outro lado, temos o cidadão comum, membro de uma maioria a quem o conhecimento é negado e para quem as condições de vida são desfavoráveis, com escassez de recursos, fadado a viver em meio à superpopulação e sujeito à gravidade excessiva, que impede uma vida prolongada.

O que essa análise vem nos mostrar é que em um texto de ficção científica a discussão conceitual serve de base para explorar aspectos sociais e ideológicos da ciência. O desdobramento do problema social se dá a partir da consideração dos efeitos imagináveis (mas absolutamente especulativos) da gravidade sobre os seres vivos. Essa relação, por sua vez, é estabelecida a partir de pressupostos dados pelo procedimento da investigação científica, descrito pelo cientista da história. Não se trata, portanto, de identificar no texto, elementos que reportem às esferas C, H e S e considerá-los de forma isolada, uma vez que a própria lógica do texto ficcional articula esses três âmbitos de forma inextrincável.

\section{Um modelo semiótico para o texto de ficção científica}

Nossa análise semiótica do conto mostrou uma interconexão dos conteúdos das esferas C, H e S na construção da narrativa. Alguns pontos merecem consideração. Em primeiro lugar, verificamos que a o nível discursivo da narrativa principal se estabelece entre um ator que figurativiza o não cientista em oposição a instituições que figurativizam a ciência como poder. Acreditamos que muitas das narrativas de ficção científica trabalham em torno da oposição entre dois campos, sendo um o da ciência (como poder) e outro que a ele se opõe. A análise das narrativas subordinadas em sua relação com a narrativa principal permite, como vi- 
mos, um mapeamento da questão sociopolítica conexa com a ciência abordada na obra. Podemos verificar também que o surgimento de questões da esfera $\mathrm{H}$ se dá quando um ator filiado à ciência estabelece explicações a respeito de fenômenos da natureza ou de artefatos tecnológicos, que aparecem também como atores em narrativas subordinadas.

Com isso, podemos estabelecer um modelo sintético a partir do conto estudado, considerando três tipos de atores, que podem, de acordo com a situação, desempenhar distintas funções actanciais no nível narrativo (sujeito, antissujeito, etc.):

[Cientista]: figurativiza a ciência nos âmbitos do poder e do saber. Em algum ponto da narrativa enuncia proposições de saber a respeito da natureza ou de artefatos técnicos. Tais proposições, uma vez enunciadas, possuem potencial de repercussão no enredo, potencial esse que pode ou não ser realizado de acordo com o andamento da narrativa;

[Fenômeno]: representa um fenômeno natural ou um artefato enunciado pelo [cientista]. O enunciado do [cientista] estabelece narrativas subordinadas sobre o [fenômeno]. Nessa narrativa, podemos distinguir duas categorias de proposições sobre o [fenômeno]: as que se referem a suas relações com conceitos, leis, fenômenos, etc. da ciência e da tecnologia, que denominaremos conceitos-base e aquelas que estabelecem ligações com pessoas, que denominaremos de implicações bumanas;

[Cidadão]: figurativiza as pessoas em geral, do ponto de vista dos seus direitos e anseios como pessoa humana, e que são afetadas pelos [fenômenos]. Afetar, do ponto de vista semiótico, implica uma transformação de estado, de conjunção para disjunção ou vice-versa, de um actante em relação a um objeto de valor.

No conto "O Segredo", temos as seguintes etapas:

1. Henry Cooper, no papel de [cidadão] quer obter conhecimento sobre um [fenômeno] ocultado por [cientistas] da estação lunar;

2. uma hipótese é enunciada (narrativa subordinada) por Cooper, que assume papel de [cientista], e uma doença alienígena [fenômeno] pode afetar os [cidadãos], disjungindo-os ${ }^{2}$ do objeto de valor vida. O potencial dessa narrativa é abandonado;

3. o [cientista] Dr. Hastings enuncia a proposição sobre como o [fenômeno] gravidade afeta os seres humanos [cidadão], também disjungindo-os do objeto de valor vida, e de como sua supressão levaria à conjunção do [cidadão] com a vida.

No caso do conto analisado, o [cientista] apenas estabelece um saber no [cidadão] a respeito do poder do [fenômeno] em afetar o [cidadão]. No caso hipotético da doença alienígena o [cientista] poderia ter estabelecido o próprio poder no [fenômeno] de afetar o [cidadão], por exemplo, ao liberar a doença para o ambiente. Conforme apontamos, saber e poder são considerados competências modais associadas à fase da competência no nível narrativo (FONTANILLE, 2007, p. 176), ou seja, são objetos (abstratos) necessários como condições ao sujeito, para que de- 
O segredo de Arthur Clarke: um modelo semiótico para tratar questões sociais da ciência usando a ficção científica

pois ele possa conjugar-se com o objeto de valor definido em seu programa. O sujeito necessita, portanto, de conjugar-se ante os objetos de saber e poder como condição para depois de conjugar-se antes aos objetos de saber e poder.

A narrativa principal do conto se dá por uma relação entre [cientista] e [cidadão], relação essa que é mediada pelo [fenômeno]. A esfera C comparece nas proposições dos conceitos-base. Nesse ponto, são dadas explicações sobre o fenômeno, com variáveis graus de verossimilhança em relação à ciência real. $\mathrm{Na}$ ficção científica hard tais explicações são enfatizadas e sua proximidade com argumentos científicos reais é acentuada, como parte da própria estratégia narrativa do gênero, voltada para criar um efeito de sentido realista. A esfera $\mathrm{H}$ aparece no momento em que o cientista estabelece o saber sobre o [fenômeno]. A conjunção do [cidadão] com o saber sobre o [fenômeno] se dá, no nível fundamental, pelas etapas que iniciam na da ignorância (contrário de saber), passando-se pela negação da ignorância (o processo que leva ao saber: pesquisa, investigação), para finalmente se chegar na conjunção do [cidadão] com o saber. Finalmente, a esfera S é invocada a partir da narrativa principal, em que se estabelece a relação entre [cidadão] e [fenômeno]. Também aí o [cientista] desempenha um papel crucial, seja estabelecendo o saber sobre as implicações humanas do [fenômeno], seja estabelecendo o [poder] do fenômeno em afetar o cidadão.

Outro elemento fundamental a ser considerado é o narrador, que instaura o espaço, o tempo e os atores. Neste trabalho não nos aprofundaremos nessa questão, mas vale mencionar que a construção de elementos conceituais pelo narrador obedece a um procedimento similar ao do [cientista], mas dirigido ao leitor implícito e não ao [cidadão], ou seja, ele informa o leitor implícito a respeito de fenômenos, leis e conceitos, derivados da ciência, sempre lembrando que se trata de uma ciência ficcional, um simulacro de ciência real. O narrador, assim como o [cientista] enuncia narrativas sobre [fenômenos] em suas relações com o [cidadão]. Aqui também a exploração de conteúdos da esfera $C$ pode se dar a partir dos conceitos-base da narrativa.

\section{Conclusões e apontamentos didáticos}

Um texto de ficção científica engloba diversas possibilidades didáticas. O interesse no uso de tal recurso está na articulação entre diversas esferas do saber, não se restringindo ao aspecto conceitual. O presente trabalho procurou mostrar, através do referencial da semiótica greimasiana, que a abordagem dos conceitos em um texto de ficção científica aparece interconectada de forma indissociável a outras esferas do saber.

O modelo proposto permite estabelecer com certa precisão quais os possíveis pontos de discussão em torno das relações da ciência/tecnologia com questões sociopolíticas. Em particular, permite identificar posições ideológicas e representações culturais a respeito da atividade científica. Os conceitos, fenômenos

Rev. Ensaio | Belo Horizonte | v. 14 | n. 01 | p.209-226 | jan-abr | 2012 
e leis científicas, associados à esfera $\mathrm{C}$, dos produtos de conhecimento da ciência/tecnologia, são compreendidos não como conhecimento em si, mas inseridos na lógica de tais representações socioculturais.

Como recurso para aprendizagem conceitual, a obra de ficção científica não pode ser considerada nem em sua precisão, que pode ser deixada de lado em função de necessidades narrativas, nem em seu didatismo e sua profundidade, que se estabelecem também a partir dessas mesmas necessidades. Em relação a esses aspectos, outros materiais, especialmente produzidos para o ensino de conceitos científicos possivelmente se configurem como opções mais adequadas. Por outro lado, no que se refere à inserção dos conceitos científicos no âmbito da prática social, a ficção pode ter um importante papel a desempenhar, na medida em que expressa valores e representações sobre a ciência vista como atividade sociocultural humana.

Nesse sentido, a obra de ficção científica, como produto artístico de uma sociedade em que a ciência é um aspecto crucial, deve ser encarada menos como um recurso didático e mais como um objeto de estudo. A exibição de um filme ou a leitura de um conto como "O Segredo" talvez não deva ser entendida a partir do prisma do material didático, que ensina, ilustra ou demonstra conceitos sobre manipulação genética ou campos gravitacionais. Na lógica que estamos propondo, a relação a ser estabelecida é de outra natureza. Vê-se a obra como um dado a ser interpretado, um dado que estabelece um discurso sobre a ciência e sobre como ela se relaciona com a nossa vida.

O trabalho com a obra de ficção em sala de aula não seria, assim, análogo à leitura de um texto didático. Seria mais semelhante a uma atividade de dissecção de um animal, que se estabelece para o estudante como objeto a ser analisado. No caso do texto considerado, podemos aplicar o modelo que envolve a figurativização da ciência em confronto com a opinião pública, situação essa que pode ser verificada em muitas obras de ficção científica. Esse tipo de análise poderia servir de base para diversos tipos de atividades didáticas.

Uma análise que envolvesse três momentos poderia, em primeiro lugar, propor a identificação dos campos em disputa na história, o que eles defendem e qual a relação disso com o fazer e o saber científicos. Essa etapa poderia dar origem a uma atividade de debate ou mesmo uma encenação em grupos. Em um segundo momento, poderia ser proposta a construção das associações entre oposições semânticas, ainda que sem o uso da terminologia semiótica, resultando em um quadro similar ao da tabela 5. Isso serviria como um mapeamento dos posicionamentos ideológicos veiculados no texto e funcionaria como um exercício de interpretação.

Uma terceira etapa poderia ser o questionamento das associações. A tabela 5 pode nos dar algumas possibilidades. A associação entre "cientistas" e "privilégios" pode gerar uma questão como "Você acredita que os cientistas são privilegiados?", enquanto entre "imponderabilidade" e "vida" poderíamos ter algo 
O segredo de Arthur Clarke: um modelo semiótico para tratar questões sociais da ciência usando a ficção científica

como "Você imagina ser válida a sugestão do texto de que a baixa gravidade implicaria na extensão do tempo de vida?". Com isso, seria possível articular discussões mais conceituais, como esta última, a proposições de caráter sociopolítico conexas com a ciência, como a primeira. Um questionário assim elaborado poderia servir como base para debates, para pesquisas ou para discussões em grupo, que poderiam ser seguidos com textos ou aulas mais diretivas a respeito dos temas abordados.

Com isso procuramos mostrar que a semiótica pode ser útil como instrumento de análise de textos ficcionais em um momento que precede a elaboração de atividades didáticas, sobretudo como um procedimento heurístico que permite sistematizar possíveis conteúdos a serem abordados a partir desse tipo de material.

\section{NOTAS}

${ }^{1}$ Discussões sobre a ciência ficcional e seu papel nas obras de ficção científica podem ser encontradas em Asimov (1984, p. 27) e Tavares (1992, p. 11).

${ }^{2}$ Disjungir refere-se à disjunção, operação abstrata que se opõe à conjunção. Em termos simples, o verbo empregado em textos de semiótica, significa a operação que aparta um sujeito de um objeto.

\section{BIBLIOGRAFIA}

ALLEN, L. David. No mundo da fiç̧ão científica. São Paulo, Summus, 1976.

ASIMOV, Isaac. No mundo da ficção científica. Rio de Janeiro, Francisco Alves, 1984.

BORGWALD, James M. et al. Classroom analysis of rotating space vehicles in 2001: a space odissey. The physics teacher, College Park, v. 31, n. 07, p. 406-409, 1993.

BOSCH, M.; CHEVALLARD, Y.; GASCON, J. Science or magic? The use of models and theories in didactics of mathematics. In M. Bosch (Ed.), European research in mathematics education IV. Barcelona, pp. 1254-1263, 2006.

BRAKE, M.; THORNTON, R. Science fiction in the classroom. Physics Education, Bristol, v. 38, n. 01, p. 31-34, jan. 2003.

CHEVALLARD, Y. La transposition didactique: du savoir savant au savoir enseigné. Grenoble: La Pensée Sauvage, 1985.

DARK, M. Using science fiction movies in introductory physics. Physics Teacher, College Park, v. 43, n. 07, p. 463-465, oct. 2005.

CLARKE, A. O segredo. In: O vento solar. São Paulo, Círculo do Livro, [197?]. pp. 79-86.

FIORIN, J. L. Elementos de análise do discurso. São Paulo: Contexto, 2009.

FONTANILLE, J. Semiótica do discurso. São Paulo: Contexto, 2007.

FREUDENRICH, C. C. Sci-Fi science: using science fiction to set context for learning 
science. The science teacher, Arlington, v. 67, n. 08, p. 42-45, nov. 2000.

GREIMAS, A. J. Semântica estrutural. São Paulo: Cultrix, Edusp, 1973.

GREIMAS, A. J.; COURTÉS, J. Dicionário de semiótica. São Paulo: Contexto, 2008.

GOMES-MALUF, M.C; SOUZA, A. R. A ficção científica e o ensino de ciências: o imaginário como formador do real e do racional. Ciência \& Educação, Bauru, v. 14, n. 2, p. 271 282, 2008.

LIBÂNEO, J. C. Fundamentos teóricos e práticos do trabalho docente: estudo introdutório sobre pedagogia e didática.1990. Tese (Doutorado) - Pontifícia Universidade Católica de São Paulo, São Paulo, 1990.

MACHADO, C. A. Filmes de Ficção Científica como mediadores de conceitos relativos ao meio-ambiente. Ciência \& Educação, Bauru, v. 14, n. 2, p. 283-294, 2008.

NEVES, M. C. D. et al. Science fiction in physics teaching: improvement of science education and History of Science via informal strategies of teaching. Revista de ciências exatas e naturais, Guarapuava, v. 01, n. 02, p. 91 - 101, 2000.

PIETROFORTE, A. V. Semiótica visual: os percursos do olhar. São Paulo: Contexto, 2007.

ROSE, C. How to teach biology using the movie science of cloning people, ressurrecting the dead and combining flies and humans. Public Understand Sci., Newbury Park, v. 12, n. 03, 289-296, 2003.

TAVARES, Bráulio. O que é fição científica. $2^{a}$ edição. Coleção Primeiros Passos, 169. São Paulo, Brasiliense, 1992.

ZANETIC, J. Física também é cultura. 1989. Tese (Doutorado em Educação) - Faculdade de Educação, Uiniversidade de São Paulo, São Paulo. 1989.

Data de recebimento: 11/05/2010

Data de aprovação: 16/06/2011

Data da versão final: 16/12/2011 